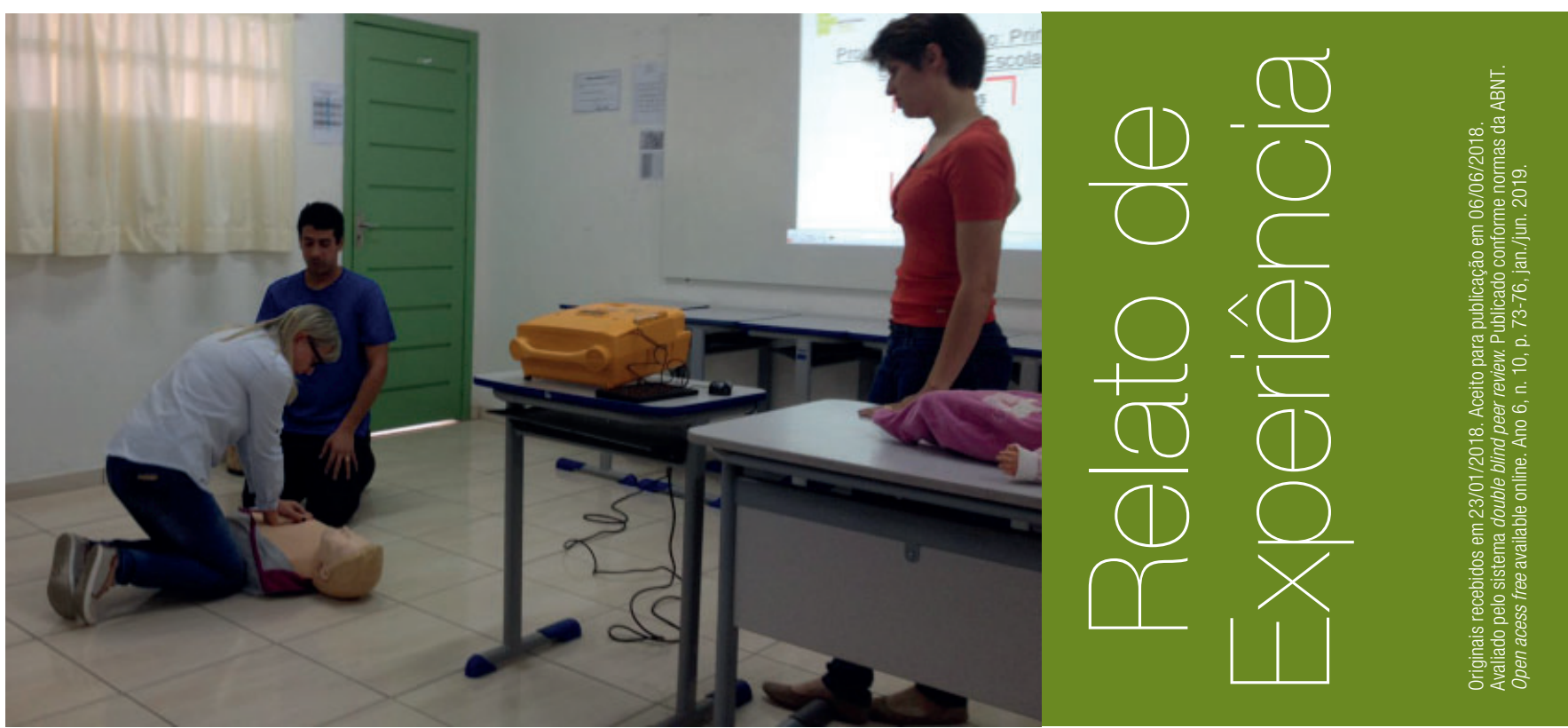

\title{
Atividades educativas de primeiros socorros para estudantes de escolas públicas de Camboriú - SC
}

Alessandra Domingues Malheiro - alessandra.malheiro@ifc.edu.br Flávia de Souza Fernandes- flavia.fernandes@ifc.edu.br

\section{RESUMO}

Trata-se de projeto de extensão que teve como objetivo desenvolver oficinas de primeiros socorros junto a estudantes do ensino fundamental de escolas públicas do município de Camboriú (SC). As oficinas foram elaboradas e aplicadas por alunos do curso de Técnico de Segurança do Trabalho do Instituto Federal Catarinense (IFC), câmpus Camboriú, com orientação e supervisão das professoras do curso. As atividades foram importantes para a comunidade, pois os alunos do curso Técnico de Segurança do Trabalho do IFC tiveram a oportunidade de aprimorar conhecimentos adquiridos na disciplina de primeiros socorros e atuaram como multiplicadores nas escolas de ensino fundamental do município, preparando outros estudantes para que possam ajudar suas famílias e comunidades em situações de urgência/emergência.

\section{PALAVRAS-CHAVE}

Primeiros socorros. Escolas. Estudantes. 


\section{ABSTRACT}

It is an extension project that aimed to develop first aid workshops with students of elementary school public schools in the city of Camboriú (SC). The workshops were elaborated and applied by students of the Occupational Safety Technician course at Instituto Federal Catarinense (IFC) Camboriú campus, with orientation and supervision of the teachers of the course. The activities were important to the community, as the students of IFC's Work Safety Technical course had the opportunity to improve knowledge acquired in the first aid discipline, and acted as multipliers in the municipal primary schools, preparing other students for help their families and communities in emergency situations.

\section{KEYWORDS}

First aid. School. Students.

\section{Relato de experiência}

Tendo o Instituto Federal Catarinense (IFC) a missão de proporcionar educação profissional comprometida com a formação cidadã, a inclusão social e o desenvolvimento regional, o mesmo necessita promover atividades a fim de detectar as necessidades da comunidade e realizar ações que possam contribuir para sanar tais necessidades. 0 IFC, além de sua função de formar cidadãos e profissionais críticos e reflexivos em diversas áreas, também se constitui como lócus de educação em saúde. Diversas são as situações da vida diária em que são necessários conhecimentos de primeiros socorros a fim de salvar a vida de uma pessoa, ou evitar 0 agravamento de uma situação de saúde. Desta forma, torna-se importante que essas habilidades sejam desenvolvidas nas diversas fases do sistema educativo.

Os alunos do curso Técnico de Segurança do Trabalho realizam a disciplina de primeiros socorros durante 0 curso, e este projeto propiciou aprimorar tais conhecimentos. Segundo Precioso (2004), uma das vias mais promissoras para promover a adoção de comportamentos saudáveis e a modificação de condutas prejudiciais à saúde e de forma sustentada é a educação para a saúde, que deve ser um direito de todos os cidadãos em qualquer fase da sua vida. Segundo o mesmo autor, a educação em saúde deve começar na família, prolongar-se por todas as fases do sistema educativo, continuar no local de trabalho e na comunidade. 0 Caderno de Atenção Básica Saúde na Escola (n 24) de 2009, do Ministério da Saúde, ressalta que a escola tem papel importante na formação de diversos valores e comportamentos. É um ambiente propício para adquirir novos conhecimentos e habilidades, por meio de troca de informações e experiências e em contato com diferentes culturas. Defende ainda que é de grande importância envolver professores, pais e alunos, em especial os adolescentes, no planejamento e na operacionalização das ações de saúde, sobretudo nas de educação em saúde, levando em conta que as mudanças e opções sugeridas devem ser passíveis de serem incorporadas à realidade social e à vida cotidiana, tanto individual como da família e da escola.

De acordo com Varella e Jardim (2011), primeiros socorros são ações que devem ser realizadas quando um acidente acontece e elas objetivam manter a pessoa viva e/ou ajudá-la a se recuperar mais rápido 0 projeto de extensão teve o objetivo geral de desenvolver oficinas (Figura 1) de primeiros socorros junto a alunos de escolas públicas de ensino fundamental da rede pública do município de Camboriú (SC) e foi desenvolvido entre agosto e dezembro de 2017.

Figura 1: Foto das oficinas.

Fonte: Dados deste projeto.

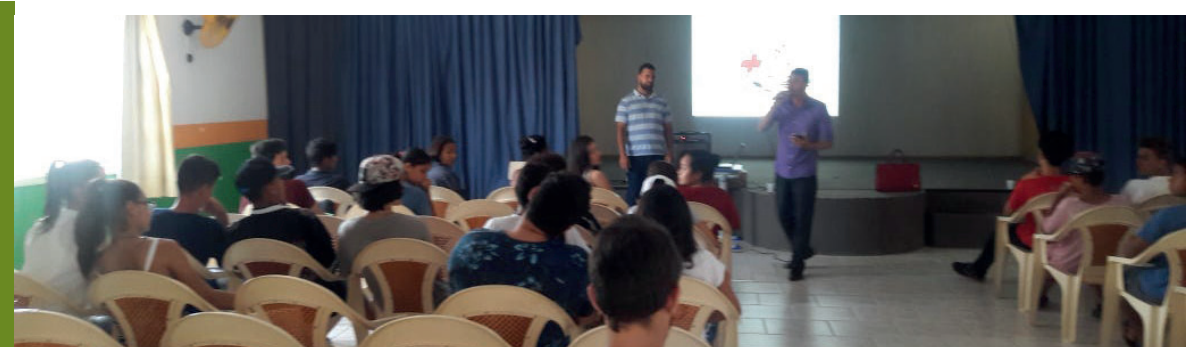


Em um primeiro momento as professoras responsáveis pelo projeto reuniram-se com a equipe diretiva da Secretaria Municipal de Educação do município para apresentar o projeto, obter autorização para a realização, bem como para iniciar contato com as escolas contempladas. Após, houve o contato com as escolas para os estudantes, do curso de Técnico de Segurança do Trabalho, estabelecerem o vínculo com o local, agendar data e horário para as oficinas e especificar os recursos a serem utilizados. Antes de iniciar a prática nas escolas, a equipe executora fez reuniões frequentes no IFC para revisar os conteúdos referentes aos primeiros socorros, elaborar e ensaiar as apresentações, sempre com a supervisão das professoras do curso. As oficinas foram executadas em cinco escolas de ensino fundamental do município, atingindo um número aproximado de 200 estudantes do quinto ao nono ano. Os principais temas abordados durante as oficinas foram: sinais vitais, ferimentos, acionamento correto de serviços de urgência e emergência, queimaduras, reanimação cardiorrespiratória, acidentes com animais peçonhentos, entre outros, sempre com demonstrações práticas (conforme Figura 2) e com linguagem adequada para a faixa etária dos jovens. Foram utilizados materiais do IFC, tais como manequim de reanimação cardiorrespiratória (adulto e infantil), vídeos e projeções de imagens com o objetivo de mostrar na prática o que estava sendo explanado.

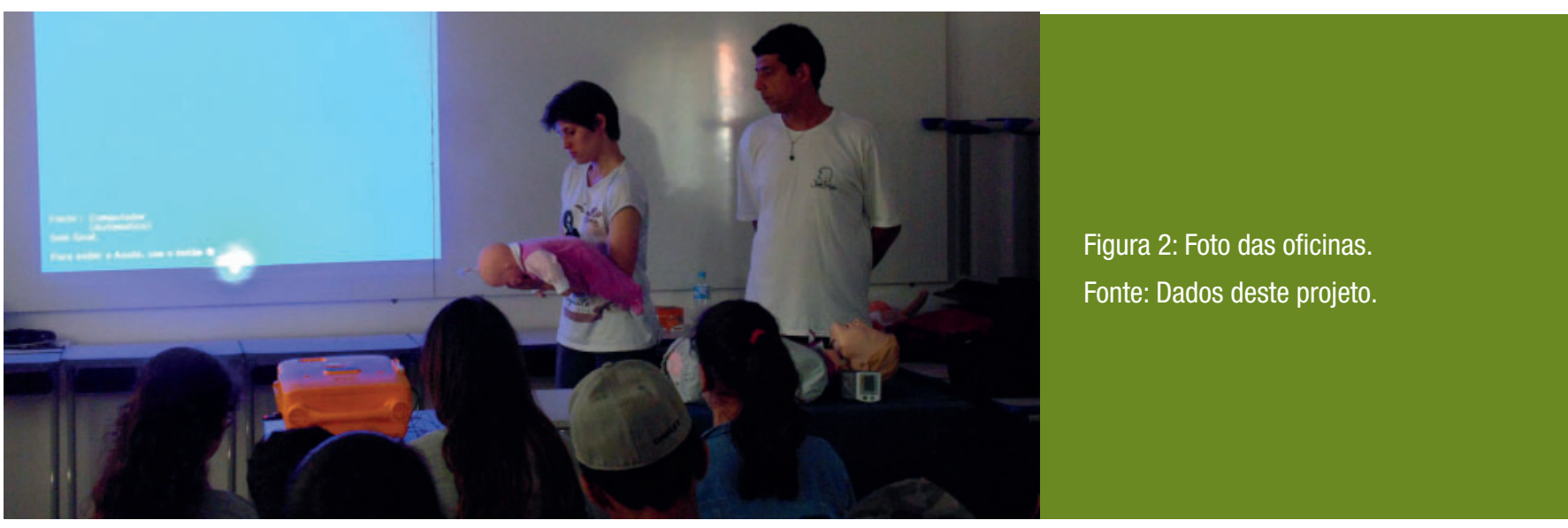

Cada oficina era iniciada com discussões a respeito do funcionamento dos Serviços de Emergência (Bombeiros, SAMU) no Brasil, enfatizando o correto acionamento dos mesmos. Após, realizavase a discussão de situações simples como desmaios, ferimentos, queimaduras leves e acidentes com animais, dando ênfase nas condutas corretas e necessidade ou não de remoção da vítima para serviços de saúde, sempre utilizando fotos e gravuras para demonstração. Posteriormente, os participantes recebiam orientações quanto a ações em caso de engasgamento e parada cardiorrespiratória. Todos eram convidados a treinar a massagem cardíaca em manequins e eram estimulados a fazer perguntas, que eram prontamente respondidas pela equipe.

0 projeto de extensão foi de extrema relevância já que os alunos do curso de Técnico de Segurança do Trabalho envolvidos no projeto aprimoraram conhecimentos adquiridos na disciplina de primeiros socorros ao planejarem e executarem as oficinas, e os alunos das escolas contempladas com o projeto desenvolveram habilidades básicas em primeiros socorros, podendo utilizar esses conhecimentos para ajudar em situações do cotidiano familiar ou da comunidade onde residem e que precisem de atendimento de primeiros socorros e acionamento correto de serviços de saúde. Verificou-se uma grande participação e interesse dos estudantes das escolas contempladas com o projeto, bem como dos professores das escolas, que também participaram das oficinas. Além disso, as escolas envolvidas solicitaram a continuidade do projeto. Em consequência deste projeto, foi oferecido curso de extensão em primeiros socorros para professores da rede escolar do município de Camboriú no primeiro semestre de 2018.

\section{Referências}

BRASIL. Caderno de Atenção Básica nº 24 - Saúde na Escola, 2009.

PRECIOSO, José. Educação para a saúde na escola: Um direito dos alunos que urge 
satisfazer. 0 Professor, n 85, III série, março-abril, p. .17-24, 2004.

VARELLA, Drauzio; JARDIM, Carlos. Primeiros socorros. São Paulo: Claro Enigma, 2011. 